Ruminta $\cdot$ S. Rosniawaty $\cdot$ A. Wahyudin

\title{
Pengujian sensitivias kekeringan dan daya adaptasi tujuh varieas padi di wilayah dataran medium Jatinangor
}

\section{Test of drought sensitivity and adaptation ability in seven varieties of rice in medium plain area Jatinangor}

\author{
Diterima : 15 Juli 2016/Disetujui : 10 Agustus 2016 / Dipublikasikan : 30 Agustus 2016
}

CDepartment of Crop Science, Padjadjaran University

\begin{abstract}
Assessment of drought resistant, adaptability, and productivity of seven varieties of rice has been conducted in medium areas wetland. The purpose of this study is to test resistant, adaptability, and productivity of seven varieties of rice to get high-yielding rice varieties that have drought-tolerant and a high yield that will be developed in the medium areas wetland. The study was designed in the form of a randomized block design experiment with 14 treatments and repeat 3 times. Tested treatment is a combination of 7 varieties of rice plants (Ciherang, Inpari 10, IR 64, Mekongga, Sintanur, Situ Bagendit, and Towuti) and 2 water control settings techniques (0 $\mathrm{cm}$ water level and intermittent). The results showed that Ciherang and Sintanur varieties has the highly potential to be developed in the medium areaswethland because it has higher production (each 8.5 ton/ ha and 8.1ton/ ha) and resistance to drought (Stress Sensitivity Index, 2.12.5 ) and have high adaptation to the environment (Index Adaptation, 1:16 - 1:29). Sintanur and Ciherang varieties with intermittent or $0 \mathrm{~cm}$ water level control settings can be recommended for the medium areas rainfed wetland that a high a drought risk.
\end{abstract}

Keywords: Rice - Climate change - Drought . Water control settings

Sari Telah dilakukan pengujian sensitivitas kekeringan, daya adaptasi, dan produkstivitas tujuh varietas padi di wilayah dataran medium Jatinangor. Tujuan penelitian ini adalah untuk menguji sensitivitas kekeringan, daya adaptasi, dan produktivitas tujuh varietas tanaman padi untuk mendapatkan varietas padi unggul yang

\footnotetext{
Dikomunikasikan oleh Aep Wawan Irwan

Ruminta $^{1}$. S. Rosniawaty ${ }^{1}$. A. Wahyudin ${ }^{1}$

${ }^{1}$ Staf Pengajar Fakultas Pertanian Universitas

Padjadjaran,

Korespondensi: r_ruminta@yahoo.com
}

tahan kekeringan dan memiliki daya hasil tinggi yang akan dikembangkan pada lahan sawah dataran medium. Penelitian ini dirancang dalam bentuk eksperimen Rancangan Acak Kelompok dengan 14 perlakuan dan ulangan 3 kali. Perlakuan yang diuji merupakan kombinasi dari 7 varietas tanaman padi (Ciherang, Inpari 10, IR 64, Mekongga, Sintanur, Situ Bagendit, dan Towuti) dan 2 pemberian air (macak-macak dan intermiten). Hasil penelitian menunjukkan bahwa varietas Sintanur dan Ciherang sangat berpotensi untuk dikembangkan pada sawah dataran medium karena mempunyai produktivitas lebih tinggi (masing-masing 8.5 ton/ha dan 8.1 ton/ha) dan tahan kekeringan (Indeks sensitivitas kekeringan, 2.1-2.5) dan mudah beradaptasi dengan lingkungan (Indeks adaptasi, 1.16 -1.29). Varietas Sintanur dan Ciherang dengan teknik pemberian intermiten atau macak-macak dapat direkomendasikan untuk lahan sawah tadah hujan pada dataran medium yang rentan kekeringan.

Kata kunci: Padi · Perubahan iklim · Kekeringan . Teknik pemberian air

\section{Pendahuluan}

Adanya perubahan iklim mengancam sistem produksi tanaman padi dan oleh karena itu juga mengancam mata pencaharian dan ketahanan pangan untuk jutaan orang yang bergantung pada pertanian. Pengaruh perubahan iklim terhadap sektor pertanian di Indonesia termasuk Jawa Barat sudah terasa dan menjadi kenyataan. Perubahan ini diindikasikan antara lain oleh adanya bencana banjir, kekeringan (musim kemarau yang panjang) dan bergesernya musim hujan (Aldrian, 2007; Indonesia Country Study on Climate Change, 1998). Dalam beberapa tahun terakhir ini pergeseran musim hujan menyebabkan bergesernya musim tanam dan 
panen komoditi pangan (padi dan palawija), sedangkan banjir dan kekeringan menyebabkan gagal tanam, gagal panen, dan bahkan menyebabkan puso (Boer dan Faqih, 2004; Syahbuddin, et al., 2004).

Pada lahan sawah dataran medium yang umumnya merupakan sawah tadah hujan, perubahan pola hujan mungkin adalah ancaman terbesar, karena begitu banyak petani sawah mengandalkan langsung pada hujan untuk kegiatan pertanian dan mata pencahariannya, setiap perubahan curah hujan menyebabkan resiko besar (Ruminta, dkk, 2009; Ruminta dan Handoko. 2011). Pertanian tadah hujan sangat rentan terhadap perubahan iklim, jika praktek bertani tetap tidak berubah Suhu yang lebih tinggi akan menantang sistem pertanian. Tanaman sangat sensitif terhadap suhu tinggi selama tahap kritis seperti berbunga dan perkembangan benih (Dorenboss and Kassam, 1979). Seringkali dikombinasikan dengan kekeringan, suhu tinggi dapat menyebabkan bencana untuk lahan pertanian. Perubahan suhu dan kelembaban udara juga dapat memicu perkembangan dan ledakan hama dan penyakit tanaman. Banjir dan kekeringan juga mempengaruhi produksi pertanian. Banjir dan kekeringan yang berkepanjangan akibat dari pengelolaan air yang tidak baik dan kapasitas yang rendah mengakibatkan penurunan produksi yang signifikan.

Air merupakan kebutuhan pokok dalam berbudidaya tanaman termasuk tanaman padi. Banjir dan kekeringan adalah merupakan permasalahan utama selain dari serangan hama dan penyakit. Efisiensi dalam penggunaan air sangat dibutuhkan sehingga dapat dihemat dan dapat meningkatkan hasil panen padi.Air merupakan kebutuhan dasar tanaman untuk dapat tumbuh, berkembang, serta berproduksi dengan baik.Semakin berkurang ketersediaan air tanah menyebabkan irigasi pada musim kemarau semakin sulit untuk dilaksanakan. Oleh karena itu, diperlukan pengembangan padi dengan sedikit air dan mampu menghasilkan produksi yang tinggi (Astuti, 2010; Juliardi dan Ruskandar, 2006). Menurut IRRI (1995) dikutip dari Setiobudi (2007), padi sawah merupakan penggunaan air paling banyak yaitu 5000 liter air untuk menghasilkan $1 \mathrm{~kg}$ gabah. Pernyataan tersebut menjelaskan bahwa kebutuhan air dalam meningkatkan hasil gabah akan bertambah, sehingga efisiensi penggunaan air sangat dibutuhkan demi tercapainya hasil padi yang maksimal dengan ketersediaan air yang ada (Hilman, 2011).
Kekeringan menjadi salah satu kendala dalam budidaya tanaman padi di Indonesia, sehingga petani lebih memilih menunda penanaman padi di lahan mereka apabila ketersediaan air irigasi dirasa kurang cukup memenuhi kebutuhan sawah mereka. Seperti diketahui bahwa para petani memiliki kebiasaan menggenangi lahan sawah dari awal musim sampai dengan panen, akan tetapi tanaman padi dapat menghasilkan produksi yang lebih tinggi apabila kebutuhan airnya dipenuhi secara tepat(Ariyanto, 2008). Kebutuhan air tanaman padi dari awal musim tanam sampai dengan panen menjadi topik utama yang perlu diuji dalam penelitian. Ketersediaan air yang cukup merupakan salah satu faktor utama dalam produksi padi sawah.Di sebagian besar daerah Asia, tanaman padi tumbuh kurang optimum akibat kelebihan air atau kekurangan air karena curah hujan yang tidak menentu dan pola lanksap yang tidak teratur (Astuti, 2010, Arafah dan Baco. 2007).

\section{Bahan dan Metode}

Penelitian dilaksanakan pada bulan Mei 2013 hingga September 2013 di Jatinangor (Dataran Medium), Kabupaten Sumedang.Penelitian ini menggunakan 7 varietas padi yaitu Ciherang, Inpari 10, IR 64, Mekongga, Sintanur, Situ Bagendit, dan Towuti dan dua teknik cera pemberian air yaitu intermitten dan macak-macak.

Percobaan ini menggunakan Rancangan Acak Kelompok (RAK) yang terdiri dari 14 kombinasi perlakuan. Kombinasi tersebut merupakan kombinasi dari pemberian air terhadap tanaman padi yang terdiri dari 2 perlakuan pemberian air yang diaplikasikan kepada tujuh macam varietas tanaman padi. Keempat belas kombinasi perlakuan tersebut masing-masing di ulang 3 kali.Sidik ragam Rancangan Acak Kelompok dianalisis dengan Uji $\mathrm{F}$ pada taraf nyata (a) 5\% dan untuk menegtahui perbedaan pengaruh dari perlakuan pengujian jarak berganda (lanjutan) dengan Uji Tukey (HSD) pada taraf nyata $5 \%$.

Parameter yang diamati dalam penilian ini adalah pertumbuhan (tinggi tanaman dan jumlah anakan), komponen hasil (jumlah malai produktif, bobor gabah per malai, dan bobot 1000 butir gabah), dan hasil (hasil gabah per petak). Seleksi varietas padi unggul kekeringan dilakukan dengan menggunakan indikator hasil, Indek Sensitivitas Kekeringan (S), dan Indeks Adaptasi (AI) (Fernandes. 1993). 


$$
\begin{gathered}
S=\frac{1-\frac{Y}{Y_{p}}}{1-\frac{X}{X_{p}}} \\
A I=\frac{Y \times Y_{p}}{X \times X_{p}}
\end{gathered}
$$

Di mana $: Y=$ Rata-rata pengamatan hasil varietas padi tertentu pada perlakuan kering; $\mathrm{Y}_{\mathrm{P}}=$ Ratarata pengamatan hasil varietas padi tertentu pada perlakuan macak-macak/basah; $X=$ Ratarata pengamatan hasil semua varietas padi pada perlakuan kering; dan $\mathrm{X}_{\mathrm{P}}=$ Rata-rata pengamatan hasil semua varietas padi pada perlakuan macak-macak/basah.Selanjutnya varietas tanaman padi dinyatakan sebagai toleran terhadap stress kekeringan jika mempunyai indeks sensitivitas kekeringan $S<0.5$, medium toleran jika $0 / 5<S<1$, dan peka jika $S>1$.

\section{Hasil dan Pembahasan}

\section{Kondisi Lingkungan}

Termpat penelitian ini mempunyai tipe iklim $C_{3}$ menurut Klasifikasi Iklim Oldeman. Lahan sawah daerah beriklim $\mathrm{C}_{3}$ ini mempunyaigrowing season pendek yaitu 5-6 bulan dan biasanya dapat ditanami padi sawah satu kali dalam setahun. Selama percobaan ratarata radiasi matahari (lama penyinaran) berkisar antara 8 - 9 jam, tinggi curah hujan antara $0 \mathrm{~mm}$ hingga $150 \mathrm{~mm}$ per bulan, rata-rata suhu udara berkisar antara $22.9^{\circ} \mathrm{C}$ hingga $24.3^{\circ} \mathrm{C}$, dan ratarata kelembaban udara $83 \%$ hingga $89 \%$, serta penguapan berkisar antara $105.5 \mathrm{~mm}$ hingga 167 203 mm (Gambar 1)

Berdasarkan data pengkuran, radiasi matahari, curah hujan, suhu, dan kelembaban serta penguapan tersebut, maka kondisi cuaca/iklim tempat penelitian cukup baik untuk pertumbuhan padi sawah, kecuali untuk curah hujan.Kebutuhan lama penyinaran optimum untuk padi sawah adalah 7-10 jam, curah hujan optimum untuk padi sawah adalah $200 \mathrm{~mm} /$ bulan, suhu udara yang baik untuk tanaman padi berkisar antara $19^{\circ} \mathrm{C}$ hingga $27^{\circ} \mathrm{C}$, dan kelembaban udara yang baik untuk tanaman pada berkisar 50\% hingga 90\%.

Parameter Pertumbuhan. Hasil uji analisis statistik tersebut menunjukkan bahwa perlakuan teknik pengaturan air memberikan pengaruh tidak nyata terhadap tinggi tanaman masing-masing varietas tanaman padi pada umur 30 HST maupun 50 HST(Tabel 1).Hasil uji statistik tinggi tanaman padi yang tidak berbeda nyata pada dua teknik pemberian air pada tanaman padi tersebut menunjukkan bahwa pertumbuhan tinggi tanaman padi tidak berbeda walaupun kondisi air lahan sawah berbeda.Pada penelitian ini perbedaan tinggi tanaman padi lebih disebabkan oleh berbedaan varietasnya karena masing-masing varietas tanaman padi mempunyai sifat dan karakreristik tersendiri.
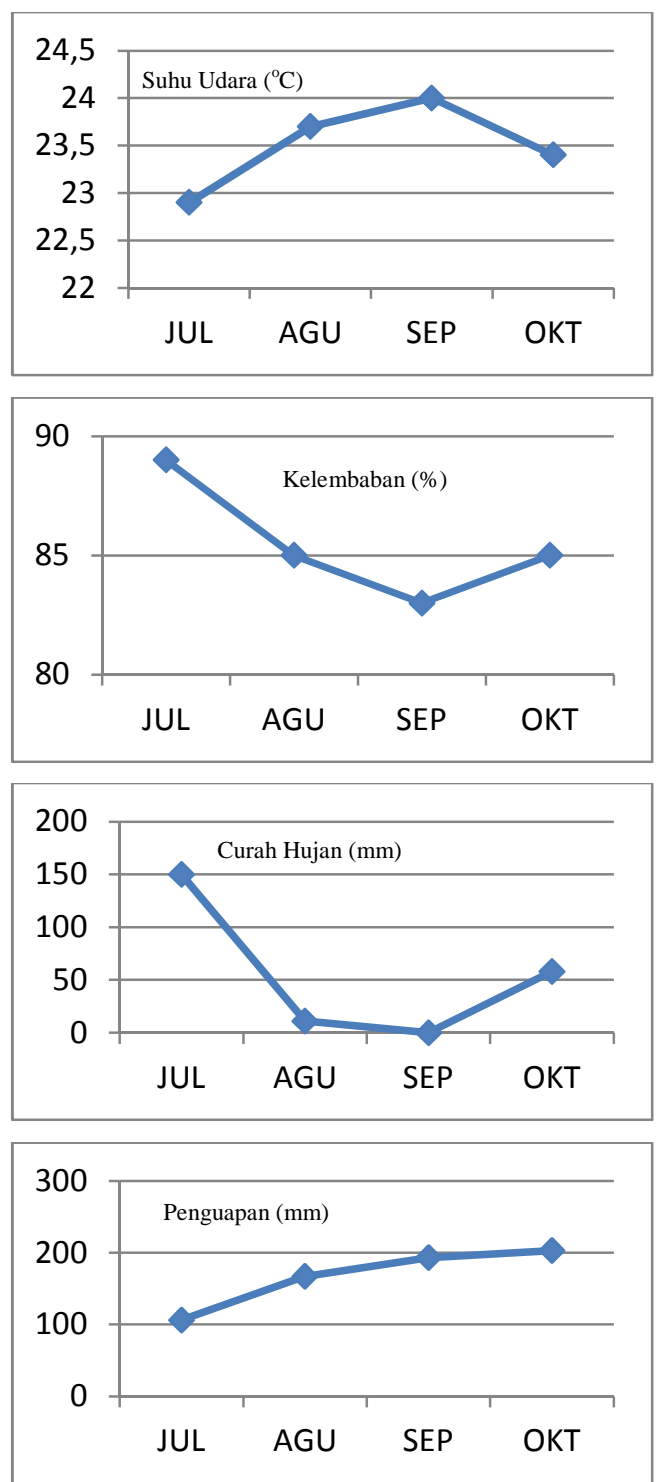

Gambar 1. Variasi Suhu, Kelembaban, Curah Hujan, dan Penguapan.

Hasil uji analisis statistik jumlah anakan per rumpun tersebut menunjukkan bahwa perlakuan teknik pengaturan air memberikan pengaruh tidak nyata terhadap jumlah anakan tanaman padi pada umur 50 HST (Tabel 1.Hasil uji statistik jumlah anakan tanaman padi yang tidak berbeda nyata pada dua teknik pemberian 
air pada tanaman padi tersebut menunjukkan bahwa pertumbuhan jumlah anakan tanaman padi tidak berbeda walaupun kondisi air lahan sawah berbeda.Anakan merupakan indikator pertumbuhan tanaman padi yang sehat atau sakit, meskipun secara genetik varietas tanaman menentukan jumlah anakan.Pada penelitian ini perbedaan jumlah anakan tanaman padi lebih disebabkan oleh berbedaan varietasnya karena masing-masing varietas tanaman padi mempunyai sifat dan karakreristik tersendiri.

Paraemeter Komponen Hasil. Hasil uji analisis jumlah malai produktif per rumpun menunjukkan bahwa perlakuan teknik pengaturan air memberikan pengaruh nyata terhadap jumlah malai produktif tanaman padi (Tabel 2).
Hasil uji statistik jumlah malai produktif tanaman padi yang berbeda nyata pada dua teknik pemberian air pada tanaman padi tersebut menunjukkan bahwa pertumbuhan jumlah malai produktif tanaman padi berbeda apabila kondisi air lahan sawah berbeda. Pada penelitian ini perbedaan jumlah malai produktif tanaman padi dipengaruhi oleh perbedaan teknik pemberian air disamping pengaruh berbedaan varietasnya dimana masing-masing varietas tanaman padi mempunyai sifat dan karakreristik genetik yang berbeda.Jumlah malai produktif berkaitan dengan jumlah anakan. Jumlah anakan yang banyak pada suatu tanaman padi memungkinkan menghasilkan jumlah malai produktif yang banyak pula.

Tabel 1 Pengaruh Teknik Pemberian Air terhadap Tinggi dan Jumlah Anakan Beberapa Varietas Tanaman Padi pada Sawah Dataran Mediun.

\begin{tabular}{|c|c|c|c|c|}
\hline \multicolumn{2}{|c|}{ Perlakuan } & \multirow{2}{*}{$\begin{array}{c}\text { Tinggi Tanaman } \\
30 \text { HST }(\mathrm{cm})\end{array}$} & \multirow{2}{*}{$\begin{array}{l}\text { Tinggi Tanaman } \\
50 \text { HST }(\mathrm{cm})\end{array}$} & \multirow{2}{*}{$\begin{array}{c}\text { Jumlah Anakan } \\
50 \text { HST }\end{array}$} \\
\hline Varietas & Teknik Pemberian Air & & & \\
\hline IR 64 & Intermiten & 59.9 abc & $66.4 \mathrm{ab}$ & $24.1 \mathrm{ab}$ \\
\hline Ciherang & Intermiten & $58.1 \mathrm{ab}$ & $68.5 \mathrm{abc}$ & $25.8 \mathrm{abc}$ \\
\hline Inpari 10 & Intermiten & $67.0 \mathrm{c}$ & $71.8 \mathrm{abc}$ & $23.3 \mathrm{ab}$ \\
\hline Sintanur & Intermiten & $62.1 \mathrm{abc}$ & $79.4 \mathrm{~cd}$ & 19.6 a \\
\hline Mekongga & Intermiten & $57.2 \mathrm{a}$ & $67.3 \mathrm{abc}$ & $29.7 \mathrm{bc}$ \\
\hline S. Bagendit & Intermiten & $61.2 \mathrm{abc}$ & $70.3 \mathrm{abc}$ & $23.1 \mathrm{ab}$ \\
\hline Towuti & Intermiten & $62.5 \mathrm{abc}$ & $69.8 \mathrm{abc}$ & $27.0 \mathrm{abc}$ \\
\hline IR 64 & Macak-macak & $58.8 \mathrm{ab}$ & 62.9 a & 20.6 a \\
\hline Ciherang & Macak-macak & $58.7 \mathrm{ab}$ & $66.4 \mathrm{ab}$ & $21.8 \mathrm{ab}$ \\
\hline Inpari 10 & Macak-macak & $64.0 \mathrm{abc}$ & $70.3 \mathrm{abc}$ & $25.3 \mathrm{abc}$ \\
\hline Sintanur & Macak-macak & $65.8 \mathrm{bc}$ & $85.6 \mathrm{~d}$ & 20.5 a \\
\hline Mekongga & Macak-macak & $61.3 \mathrm{abc}$ & $71.2 \mathrm{abc}$ & $30.3 \mathrm{bc}$ \\
\hline S. Bagendit & Macak-macak & $62.9 \mathrm{abc}$ & $68.4 \mathrm{abc}$ & $25.8 \mathrm{abc}$ \\
\hline Towuti & Macak-macak & $67.0 \mathrm{c}$ & $75.4 \mathrm{bcd}$ & $33.2 \mathrm{c}$ \\
\hline
\end{tabular}

Tabel 2. Pengaruh Teknik Pemberian Air terhadap Parameter Komponen Hasil Beberapa Varietas Tanaman Padi pada Sawah Dataran Mediun.

\begin{tabular}{|c|c|c|c|c|}
\hline \multicolumn{2}{|c|}{ Perlakuan } & \multirow{2}{*}{$\begin{array}{l}\text { Jumlah Malai per } \\
\text { Rumpun }\end{array}$} & \multirow{2}{*}{$\begin{array}{c}\text { Bobot Gabah per } \\
\text { Malai }(\mathrm{g})\end{array}$} & \multirow{2}{*}{$\begin{array}{c}\text { Bobot } 1000 \text { Butir } \\
\text { Gabah }(\mathrm{g})\end{array}$} \\
\hline Varietas & Teknik Pemberian Air & & & \\
\hline IR 64 & Intermiten & $25.2 \mathrm{abc}$ & $2.7 \mathrm{bcd}$ & $29.2 \mathrm{c}$ \\
\hline Ciherang & Intermiten & $22.8 \mathrm{abc}$ & $2.9 \mathrm{abcd}$ & $26.0 \mathrm{bc}$ \\
\hline Inpari 10 & Intermiten & $29.4 \mathrm{~cd}$ & $1.7 \mathrm{a}$ & $27.3 \mathrm{bc}$ \\
\hline Sintanur & Intermiten & $19.2 \mathrm{ab}$ & $3.6 \mathrm{~d}$ & $28.4 \mathrm{bc}$ \\
\hline Mekongga & Intermiten & $29.4 \mathrm{~cd}$ & $2.8 \mathrm{bcd}$ & $25.9 \mathrm{bc}$ \\
\hline S. Bagendit & Intermiten & $22.7 \mathrm{abc}$ & $2.4 \mathrm{abc}$ & $28.1 \mathrm{bc}$ \\
\hline Towuti & Intermiten & 25.3 abcd & 2.4 abcd & $27.6 \mathrm{bc}$ \\
\hline IR 64 & Macak-macak & $27.6 \mathrm{~cd}$ & $1.9 \mathrm{ab}$ & $27.6 \mathrm{bc}$ \\
\hline Ciherang & Macak-macak & $23.4 \mathrm{abc}$ & $3.2 \mathrm{~cd}$ & $29.6 \mathrm{c}$ \\
\hline Inpari 10 & Macak-macak & $22.7 \mathrm{abc}$ & $2.0 \mathrm{ab}$ & $28.9 \mathrm{c}$ \\
\hline Sintanur & Macak-macak & $18.4 \mathrm{a}$ & $3.5 \mathrm{~d}$ & $27.8 \mathrm{bc}$ \\
\hline Mekongga & Macak-macak & $27.1 \mathrm{~cd}$ & $2.7 \mathrm{bcd}$ & $27.7 \mathrm{bc}$ \\
\hline S. Bagendit & Macak-macak & $33.0 \mathrm{~d}$ & $1.8 \mathrm{ab}$ & $23.5 \mathrm{~b}$ \\
\hline Towuti & Macak-macak & $26.3 \mathrm{bcd}$ & $2.1 \mathrm{abc}$ & $17.9 \mathrm{~A}$ \\
\hline
\end{tabular}


Hasil uji statistik bobot gabah per malai tanaman padi yang tidak berbeda nyata pada dua teknik pemberian air pada tanaman padi tersebut menunjukkan bahwa bobot gabah per malai tanaman padi tidak berbeda walaupun kondisi air lahan sawah berbeda.Pada penelitian ini perbedaan bobot gabah per malai tanaman padi lebih dipengaruhi oleh perbedaan varietasnya dimana masing-masing varietas tanaman padi mempunyai sifat dan karakreristik genetik yang berbeda.Bobot gabah per malai berkaitan dengan jumlah butir gabah per malai.Jumlah butir gabah per malai bergantung kepada kegiatan tanaman pada fase reproduksi.Kegiatan fotosintesis selama fase ini menentukkan jumlah butir per malai.Zat pati pada butir berasal dari dua seumber yaitu dari hasil asimilasi sebelum pembungaan yang disimpan dalam jaringan batang dan daun dan hasil asimilasi selama fase pematangan.Semakin banyak jumlah malai dalam satu rumpun tanaman padi maka semakin pendek malai yang dihasilkan dan sebaliknya.Semakin panjang malai pada tanaman padi maka semakin banyak pula jumlah butir gabah yang dihasilkan sehingga semakin besar pula bobot gabah per malainya (Makarim dan Suhartatik, 2009).

Hasil uji analisis statistik bobot 1000 butir gabah menunjukkan bahwa perlakuan teknik pengaturan air memberikan pengaruh berbeda nyata terhadap bobot 1000 butir gabah (Tabel 2).Hasil uji statistik bobot 1000 butir gabah tanaman padi yang berbeda nyata pada dua teknik pemberian air pada tanaman padi tersebut menunjukkan bahwa bobot 1000 butir gabah tanaman padi berbeda jika kondisi air lahan sawah berbeda.Pada penelitian ini perbedaan bobot 1000 butir gabah tanaman padi dipengaruhi oleh kondisi air lahan dan perbedaan varietasnya dimana masing-masing varietas tanaman padi mempunyai sifat dan karakreristik genetik yang berbeda.Melihat kecenderungan yang lebih tinggi pada teknik pemberian air secara intermiten, mengindikasikan bahwa teknik pemberian air secara intermiten lebih baik dibanding teknik pemberian air secara macak-macak sehingga menghasilkan rata-rata bobot 1000 butir gabah yang lebih berat. Pemberian air melalui teknik pengairan intermiten dapat membantu proses metabolisme yang mendukung pengisian butir padi lebih baik dibanding pemberian air dengan teknik pengairan macak-macak. Pemberian air secara intermiten mengindikasikan pertumbuhan jari- ngan akar lebih sempurna sehingga proses pengangkutan unsur hara untuk kebutuhan metabolism lebih lancar. Proses metabolism yang lancar menyebabkan fase pengisian butir padi lebih baik, sehingga bobot yang dihasilkan lebih tinggi.

Parameter Hasil. Hasil uji analisis statistik hasil gabah per rumpun tersebut menunjukkan bahwa perlakuan teknik pengaturan air memberikan pengaruh berbeda tidak nyata terhadap bobot gabah per rumpun (Tabel 3).Hasil uji statistik hasil gabah per rumpun tanaman padi yang berbeda tidak nyata pada dua teknik pemberian air pada tanaman padi tersebut menunjukkan bahwa berat gabah per rumpun tanaman padi tidak berbeda walapun kondisi air lahan sawah berbeda.Pada penelitian ini perbedaan berat gabah per rumpun tanaman padi lebih dipengaruhi oleh perbedaan varietasnya dimana masing-masing varietas tanaman padi mempunyai sifat dan karakreristik genetik yang berbeda.

Analisis statistik hasil gabah per petak (ukuran $3 \mathrm{~m} \times 2.5 \mathrm{~m}$ ) tanaman padi pada Tabel 3 menunjukkan bahwa perlakuan teknik pengaturan air memberikan pengaruh berbeda tidak nyata terhadap berat gabah per petak.Hasil uji statistik hasil gabah per petak tanaman padi yang berbeda tidak nyata pada dua teknik pemberian air pada tanaman padi tersebut menunjukkan bahwa berat gabah tanaman padi tidak berbeda walapun kondisi air lahan sawah berbeda.Pada penelitian ini perbedaan bobot gabah tanaman padi lebih dipengaruhi oleh perbedaan varietasnya dimana masing-masing varietas tanaman padi mempunyai sifat dan karakreristik genetik yang berbeda.

Perbedaan yang tidak nyata pada berat gabah per petak (ataupun per hektar) dari ke tujuh varietas padi yang diberi air secara intermiten maupun macak-macak menunjukkan bahwa ke tujuh varietas padi tersebut akan sama baiknya apabila dibudidayakan dengan kondisi pengairan intermiten ataupun kondisi pengairan macakmacak. Teknik pemberian air secara intermiten maupun secara macak-macak dapat memenuhi kebutuhan air dari ke tujuh varietas tanaman padi tersebut.Hal ini berarti bahwa lahan sawah tidak selalu harus digenangi air. Jadi teknik pemberian air secara intermiten maupun secara macak-macak merupakan salah satu pilihan adaptasi strategis dalam menghadapi bekurangnya ketersediaan air akibat perubahan iklim pada lahan sawah tadah hujan dataran medium. 
Tabel 3. Pengaruh Teknik Pemberian Air terhadap Hasil Gabah Beberapa Varietas Tanaman Padi pada Sawah Dataran Mediun.

\begin{tabular}{|c|c|c|c|c|}
\hline \multicolumn{2}{|c|}{ Perlakuan } & \multirow{2}{*}{$\begin{array}{l}\text { Hasil Gabah per } \\
\text { Rumpun }(\mathrm{g})\end{array}$} & \multirow{2}{*}{$\begin{array}{l}\text { Hasil Gabah per } \\
\text { Petak }(\mathrm{kg})\end{array}$} & \multirow{2}{*}{$\begin{array}{c}\text { Hasil Gabah per } \\
\text { Hektar (ton) }\end{array}$} \\
\hline Varietas & Teknik Pemberian Air & & & \\
\hline IR 64 & Intermiten & $69.2 \mathrm{bcd}$ & $6.5 \mathrm{ab}$ & 7.3 \\
\hline Ciherang & Intermiten & $66.0 \mathrm{abcd}$ & $7.2 \mathrm{ab}$ & 8.1 \\
\hline Inpari 10 & Intermiten & $51.3 \mathrm{ab}$ & $5.0 \mathrm{a}$ & 5.6 \\
\hline Sintanur & Intermiten & $68.4 \mathrm{bcd}$ & $7.5 \mathrm{~b}$ & 8.5 \\
\hline Mekongga & Intermiten & $82.1 \mathrm{~d}$ & $6.9 \mathrm{ab}$ & 7.8 \\
\hline S. Bagendit & Intermiten & $54.7 \mathrm{abc}$ & $6.5 \mathrm{ab}$ & 7.3 \\
\hline Towuti & Intermiten & 61.1 abcd & $6.0 \mathrm{ab}$ & 6.8 \\
\hline IR 64 & Macak-macak & $53.1 \mathrm{abc}$ & $5.7 \mathrm{ab}$ & 6.5 \\
\hline Ciherang & Macak-macak & $74.1 \mathrm{~cd}$ & $6.8 \mathrm{ab}$ & 7.7 \\
\hline Inpari 10 & Macak-macak & $44.5 \mathrm{a}$ & $5.7 \mathrm{ab}$ & 6.4 \\
\hline Sintanur & Macak-macak & 63.9 abcd & $7.2 \mathrm{ab}$ & 8.1 \\
\hline Mekongga & Macak-macak & 71.9 bcd & $6.8 \mathrm{ab}$ & 7.7 \\
\hline S. Bagendit & Macak-macak & $58.4 \mathrm{abc}$ & $6.5 \mathrm{ab}$ & 7.4 \\
\hline Towuti & Macak-macak & $56.4 \mathrm{abc}$ & $5.8 \mathrm{ab}$ & 6.6 \\
\hline
\end{tabular}

Tabel 4. Nilai Indeks Sensitivitas Kekeringan (S) dan Indeks Adaptasi (AI) Beberapa Varietas Tanaman Padi pada Sawah Dataran Mediun.

\begin{tabular}{lcc}
\hline \hline \multicolumn{1}{c}{ Varietas Padi } & $\begin{array}{c}\text { Indeks Sensitivitas } \\
\text { Kekeringan }(S)\end{array}$ & Indeks Adaptasi $(A I)$ \\
\hline IR 64 & 5.6 & 0.89 \\
Ciherang & 2.5 & 1.16 \\
Inpari 10 & 5.2 & 0.67 \\
Sintanur & 2.1 & 1.29 \\
Mekongga & 0.6 & 1.13 \\
Situ Bagendit & 0.3 & 1.01 \\
Towuti & 1.5 & 0.84 \\
\hline \hline
\end{tabular}

Indeks Sensitivitas Kekeringan dan Indeks Adaptasi. Hasil analisis Indeks Sensitivitas kekeringan (S) dan Indeks Adapatasi (AI) pada Tabel 4 menunjukkan bahwa Varietas Situ Bagendit, Mekongga, dan Towuti mempunyai nilai indeks sensitinitas kekeringan yang rendah (0.3-1.5). Ketiga varietas padi tersebut mengindikasikan tahan kekeringan namun produksinya masih di bawah varietas Sintanur dan Ciherang yang mempunyai indeks sensitivitas kekeringan medium $(2.1$ - 2.5). Sementara itu untuk varietas IR 64 dan Inpari 10 mempunyai indeks sensivitas kekeringan yang tinggi $(5.2-5.6)$. Hal ini menunjukkan bahwa kedua varietas padi tersebut sangat tidak tahan terhadap kekeringan.

Indeks adaptasi ketujuh varietas padi yang diteliti cukup bervariasi berkisar antara 0.67 hingga 1.29 (Tabel 4).Berdasarkan tabel tersebut menunjukan bahwa varietas Inpari 10 dan Towuti mempunyai nilai indeks adaptasi rendah (0.67-0.84). Hal ini mengindikasikan bahwa kedua varietas tersebut kurang dapat beradaptasi di banding varietas padi lainnya.Sementara itu untuk varietas Sintanur dan Ciherang mempunyai indeks adaptasi yang cukup tinggi (1.16-1.29) menunjukkan bahwa bahwa kedua varitas padi tersebut dapat beradaptasi dengan lingkungan dengan kondisi air tanah yang berbeda dengan potensi hasil yang tinggi.

Berdasarkan nilai indeks sensitivitas kekeringan dan indeks adaptasi tersebut menunjukkan bahwa varietas Sintanur dan Ciherang dapat direkomendasikan sebagai varietas yang mempunyai potensi tinggi untuk dikembangkan pada lahan sawah dataran medium dengan teknik pengairan macak-macak atau intermiten karena mempunyai potensi hasil tinggi dan cukup tahan kekeringan serta dapat beradaptasi dengan kondisi air tanah yang berbeda.

\section{Kesimpulan dan Saran}

Berdasarkan penelitian seleksi varietas tanaman padi unggul yang tahan kekeringan di lahan sawah dataran medium ini dapat diambil kesimpulan sebagai berikut: 
1. Varietas Sintanur menunjukkan hasil gabah lebih besar dibanding varietas Inpari 10 akan tetapi tidak berbeda nyata dengan varietas IR 64, Ciherang, Mekongga, Situ Bagendit, dan Towuti pada lahan sawah dengan teknik pemberian air secara secara intermiten.

2. Tanaman padi varietas Sintanur dan Ciherang sangat berpotensi untuk dikembangkan pada sawah dataran medium karena mempunyai produksi lebih tinggi (masingmasing 8.5 ton/ha dan 8.1 ton/ha) dan tahan kekeringan (mempunyai indeks sensitivitas kekeringan, 2.1-2.5 atau medium) dan mudah beradaptasi dengan lingkungan (Indeks adaptasi relatif tinggi, 1.16 -1.29).

\section{Daftar Pustaka}

Aldrian E. 2007. Decreasing trends in annual rainfalls over Indonesia: A threat for the national water resources? Published by Journal of BMG. Jakarta.

Arafah, Razak, N., dan Baco, D. 2007. Pengelolaan Air Sistem Basah Kering (AWD) Pada Padi Sawah.BPTP Sulawesi Selatan.

Ariyanto, Dwi Priyo. 2008. Sistem Pemberian Kebutuhan Air Untuk Lahan Pertanian. Fakultas Pertanian Universitas Sebelas Maret. Surakarta.

Astuti, N.D. 2010. Pengaruh Sistem Pengairan Terhadap Pertumbuhan dan Produktivitas Beberapa Varietas Padi Sawah. IPB.

Boer R., and A. Faqih, 2004: Current and Future Rainfall Variability in Indonesia. AIACC Technical Report 021.

BPS. 2009. Produksi tanaman padi seluruh provinsi tahun 2000-2009. Badan Pusat Statistik Republik Indonesia. Jakarta.
Dorenboss, J. And A. Kassam. 1979. Yield Response to Watter. FAO Irrigation and Drainage Paper. Rome. 2nd Edition.

Hilman. 2011. Teknologi Hemat Air di Lahan Sawah Irigasi. BPTP Sulawesi Selatan.

Indonesia Country Study on Climate Change. 1998. Vulnerability and Adaptation Assessments of Climate Change in Indonesia. The Ministry of Environment the Republic of Indonesia. Jakarta.

Juliardi, L., dan Ruskandar, A. 2006. Teknik Mengairi Padi Kalau Macak-macak Cukup Mengapa Harus Digenang?.BB Penelitian Padi.

Makarim, A. dan Suhartatik, E. 2009. Morfologi dan Fisiologi Tanaman Padi. Balai Besar Penelitian Taanaman Padi.

Ruminta dan Handoko. 2011a. Kajian Risiko dan Adaptasi Perubahan Iklim Pada Sektor Peranian di Sumatera Selatan. Laporan Penelitian. KLH Jakarta

Ruminta dan Handoko. 2011b. Kajian Risiko dan Adaptasi Perubahan Iklim Pada Sektor Peranian di Malang Raya. Laporan Penelitian. KLH Jakarta

Ruminta, Tati Nurmala, dan Warid Ali Qosim. 2009. Analisis Dampak Perubahan Pola Curah Hujan Terhadap Sistem Pertanian Tanaman Pangan Lahan Kering di Jawa Barat. Laporan Penelitian. Faperta Unpad Jatinangor.

Setiobudi, D. 2007. Teknik Pengelolaan Air Pada Padi Hibrida. BPTP Padi Subang.

Syahbuddin, H., Manabu D. Yamanaka, and Eleonora Runtunuwu. 2004. Impact of Climate Change to Dry Land Water Budget in Indonesia: Observation during 1980-2002 and Simulation for 2010-2039. Graduate School of Science and Technology.Kobe University.Publication in Process. 